\title{
Human ZP4 is not sufficient for taxon-specific sperm recognition of the zona pellucida in transgenic mice
}

\author{
Belinda Yauger ${ }^{1}$, Nathan A Boggs and Jurrien Dean \\ Laboratory of Cellular and Developmental Biology, NIDDK, National Institutes of Health, Bethesda, \\ Maryland 20892, USA and ${ }^{1}$ Combined Federal Fellowship in Reproductive Endocrinology and Infertility, Bethesda, \\ Maryland 20892, USA
}

Correspondence should be addressed to J Dean; Email: jurrien@helix.nih.gov

\begin{abstract}
The molecular basis of human fertilization remains enigmatic. Mouse models are often used to study sperm-egg recognition, but the mouse zona pellucida surrounding ovulated eggs contains three proteins (ZP1, ZP2, and ZP3) whereas the human zona contains four (ZP1, ZP2, ZP3, and ZP4). Human sperm are fastidious and recognize human but not mouse eggs. Transgenic mouse lines were established to ascertain whether human ZP4 is the sole determinant of human sperm binding. Human ZP4 expressed in transgenic mice had a molecular mass similar to the range of native protein isoforms and was incorporated into the extracellular zona matrix. Transgenic females were fertile with normal litter sizes. Mouse sperm readily recognized transgenic ovulated eggs, but human sperm did not. We conclude that human ZP4 is not sufficient to support human sperm binding to the zona pellucida in transgenic mice and that other zona proteins may be needed for human gamete recognition.

Reproduction (2011) 141 313-319
\end{abstract}

\section{Introduction}

The zona pellucida, an acellular glycoprotein matrix surrounding mammalian eggs and early embryos, mediates sperm-egg interaction, provides a postfertilization block to polyspermy, and protects the embryo prior to implantation (Yanagimachi 1994). The mouse zona contains three glycoproteins (ZP1, ZP2, and ZP3) and the human zona contains four (ZP1, ZP2, ZP3, and $Z$ P4). Homologous genes encoding the four proteins are present on syntenic chromosomes in each taxon (Hoodbhoy et al. 2005), but mouse Zp4 contains multiple stop codons and does not express the cognate protein (Lefièvre et al. 2004). Because of multiple pre(habitat, physiognomy, and mating behavior) and post-zygotic (aneuploidy) barriers, the evolutionary basis of taxon-specific sperm-egg recognition among internally fertilizing mammals is not immediately obvious $\left(\mathrm{O}^{\prime}\right.$ Rand 1988). Nevertheless, human sperm exhibit stringent self-recognition and do not bind to mouse eggs. In contrast, mouse sperm recognize eggs from a taxonomically diverse group of mammals, including humans (Bedford 1977). Taking advantage of this dichotomy, it is possible to explore the molecular basis of sperm-egg interactions with 'loss-of-function' mouse lines deficient in single zona proteins and 'gain-of-function' transgenic mice expressing human zona proteins.
Using gene-targeting and embryonic stem-cell technologies, mice lacking individual zona proteins have been established. Zp1 null female mice form a zona pellucida that is thinner than normal, but sperm bind and fertilize eggs in vitro. Thus, ZP1 is not essential for sperm-egg recognition in mice (Rankin et al. 1999). However, Zp1 null females have decreased fecundity because pre-implantation embryos cannot survive precocious escape from the zona matrix during passage through the oviduct. $Z p 2$ and $Z p 3$ null mouse lines have also been established, but in the absence of either protein, no zona matrix is present surrounding ovulated eggs and the zona-free eggs are quickly absorbed to the epithelial lining of the oviduct. Therefore, the role of either ZP2 or ZP3 in sperm-egg recognition was indeterminate in these studies (Rankin et al. 1998, 2001). Transgenic mouse lines expressing either human $Z P 2$ or $Z P 3$ incorporate the human protein into the zona pellucida but, under the reported experimental conditions, the presence of either human protein was not sufficient to support human sperm binding even when crossed into the corresponding Zp2 or Zp3 null background (Rankin et al. 1998, 2003).

Although not detected in mice (Boja et al. 2003), ZP4 protein is present in multiple different species including humans, chimpanzees, cows, pigs, dogs, cats, and rats and has been reported to play a role in sperm-egg 
recognition in some (Prasad et al. 1996, Topper et al. 1997, Govind et al. 2000). The specificity of human sperm binding could reflect a taxon-independent need for four zona proteins to form a zona structure distinct from that formed with three zona proteins or a taxonspecific need for human ZP4 protein. The first hypothesis was tested with rats that have a zona pellucida composed of four zona proteins that are $62-70 \%$ identical to the human homologues. Although mouse and rat sperm bound to rat eggs, human sperm did not. Thus, a heterologous zona pellucida composed of four zona proteins is not sufficient for human sperm attachment under the experimentally described conditions (Hoodbhoy et al. 2005). We now test the second hypothesis by establishing a 'gain-of-function' assay in which human $Z P 4$ is expressed in transgenic mice to investigate the molecular basis of human and mouse gamete recognition.

\section{Results}

\section{Establishment of human ZP4 transgenic mouse lines}

Human ZP4 (11.6 kb, including $2.4 \mathrm{~kb}$ of promoter) was isolated from a BAC and subcloned to provide a DNA fragment (Fig. 1A), which was injected into the pronucleus of one-cell embryos to establish transgenic mouse lines. The transgene was detected by PCR and Southern blot (data not shown) in 5 out of 25 pups (20\%) and 3 ( 2 females and 1 male) were used to establish stable transgenic lines. Two founder lines were tested for taxon specificity of sperm binding and one (human ZP4Tg) was utilized in this study.

Tissue-specific expression of the transgene was assayed by RT-PCR of total RNA isolated from mouse brain, muscle, heart, lung, kidney, liver, uterus, spleen, testes, and ovary. Using primers specific for ZP4 (Fig. 1A), the expression was detected only in the ovary
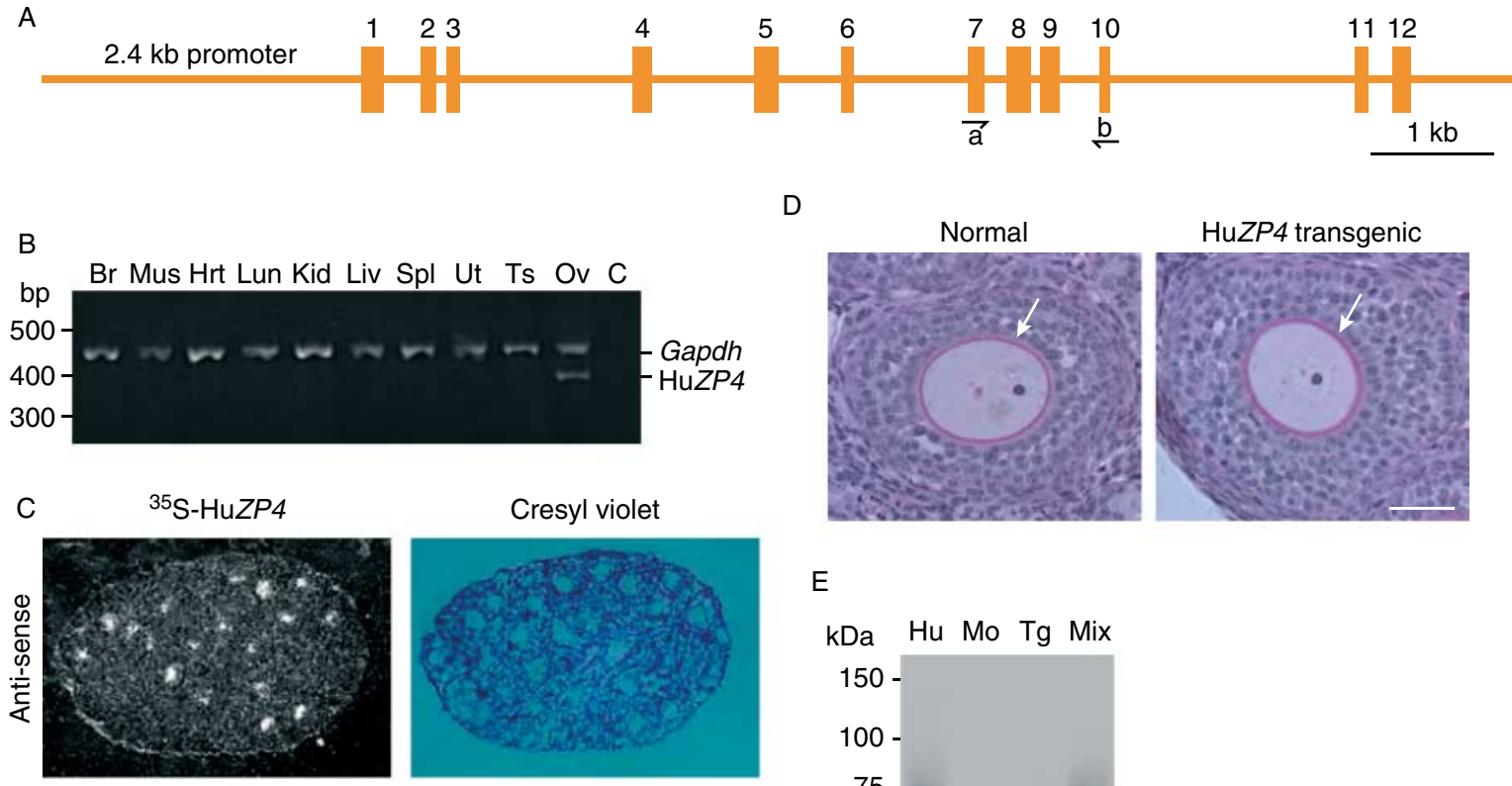

D
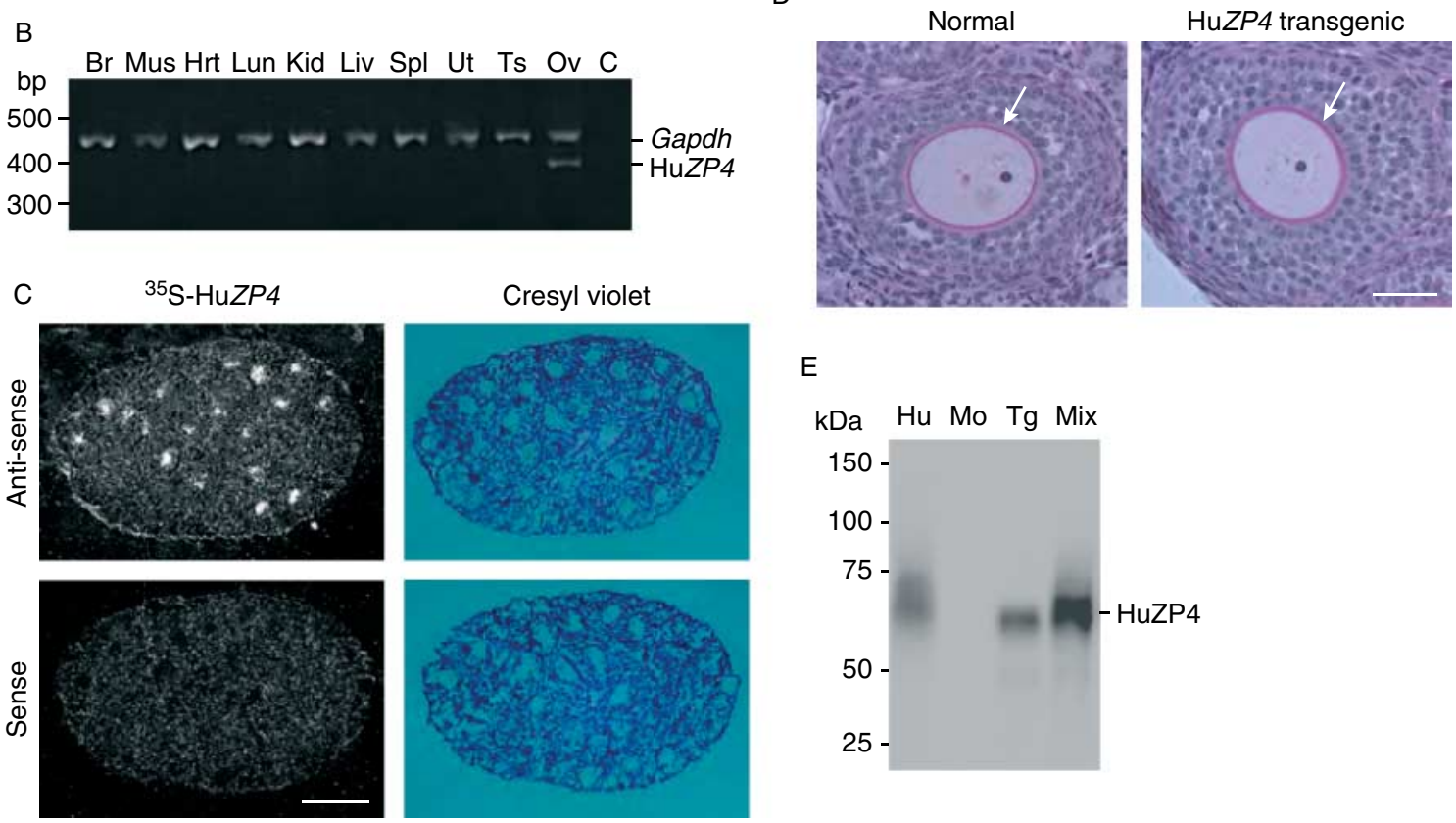

$\mathrm{E}$

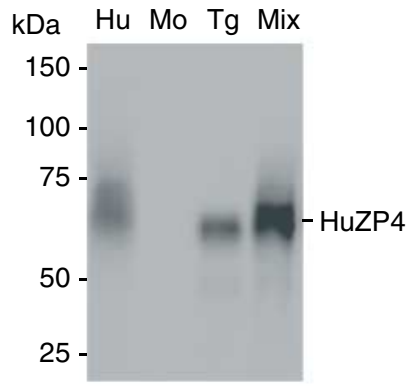

Figure 1 Transgenic mice expressing human ZP4. (A) Schematic of $11.6 \mathrm{~kb}$ human ZP4 gene locus composed of a $2.4 \mathrm{~kb}$ promoter, $8.2 \mathrm{~kb}$ coding region, and $1.0 \mathrm{~kb} \mathrm{3'}$ of the last exon. Exons are indicated by Arabic numbers and PCR primers by arrowheads. (B) Tissue-specific expression of human ZP4 was determined by RT-PCR. Total RNA was isolated from the brain (Br), muscle (Mus), heart (Hrt), lung (Lun), kidney (Kid), liver (Liv), spleen (Spl), uterus (Ut), testes (Ts), and ovary (Ov) of transgenic mice. Ovarian RNA without reverse transcriptase was a negative control (C). After RT to obtain ssDNA, PCR amplification was performed with exon-specific primers (A) to distinguish ssDNA (485 bp) from genomic DNA (1052 bp). Gapdh expression (572 bp) was used as an internal control for RNA integrity and quantity. Molecular mass markers are indicated at the left. (C) In situ hybridization of normal and human ZP4 transgenic ovarian sections. Specific ${ }^{35}$ S-labeled sense and anti-sense human ZP4 cRNA probes were hybridized to OCT-embedded ovarian sections from 15-day-old transgenic females. Sections were viewed with bright- and darkfield microscopy. (D) Plastic-embedded ovarian sections from 3- to 4-week-old human ZP4 transgenic and normal female mice. Sections were stained with periodicacid Schiff's reagent to highlight the zona pellucida (arrow), surrounding developing oocytes and counterstained with hematoxylin. (E) Immunoblot of human and mouse eggs. Lane $1(\mathrm{Hu})$, uninseminated, immature human oocyte (2); lane 2 (Mo), normal mouse eggs (30); lane 3 (Tg), human ZP4 transgenic eggs (30); and lane 4 (Mix), mixture of lanes $1(\mathrm{Hu})$ and $3(\mathrm{Tg})$. Blot was probed with a MAB specific to human ZP4 and detected with HRP-conjugated secondary antibodies and chemiluminescence. Molecular weights are indicated to the left. 

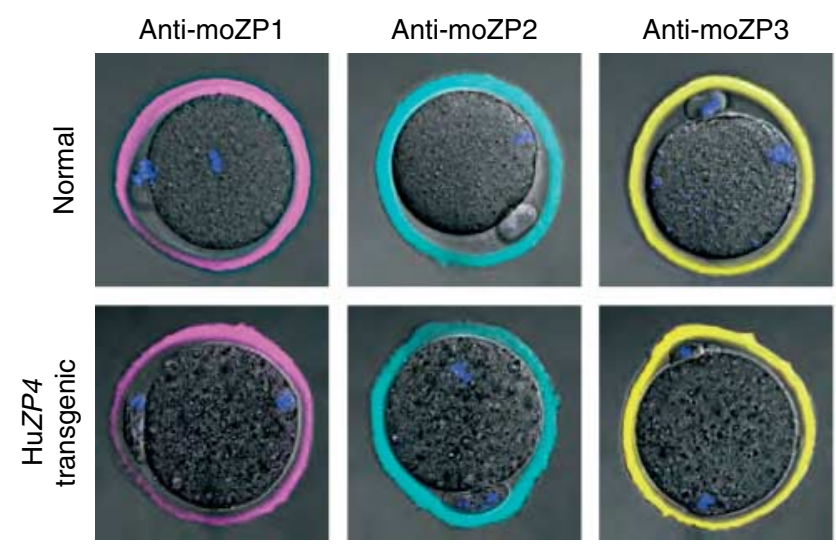

of transgenic mice (Fig. 1B). Within the ovary, the expression was localized to growing oocytes by in situ hybridization of ovarian sections from 15-day-old transgenic females using human ZP4-specific ${ }^{35} \mathrm{~S}$-labeled anti-sense cRNA probes. The signal observed in normal oocytes (data not shown) or using control sense probes was no greater than background (Fig. 1C).

Ovarian histology, including the appearance of the zona pellucida, in transgenic animals was indistinguishable from normal controls (Fig. 1D). Eggs from normal and ZP4 transgenic mice were analyzed on immunoblots probed with a MAB to human ZP4 (Fig. 1E). Although the band corresponding to ZP4 in the human sample was diffuse, the smaller isoforms appeared to co-migrate with the ZP4 expressed in transgenic mouse eggs. To determine whether the lower size range of ZP4 in the human sample overlapped with the size of ZP4 expressed in the mouse, the two samples were mixed together and a single band was observed (Fig. 1E). Thus, native and recombinant ZP4 have an overlapping molecular mass 65-70 kDa. Using confocal microscopy and MABs to image ovulated eggs, human ZP4 co-localized with mouse ZP1, ZP2, and ZP3 in the extracellular zona pellucida matrix (Fig. 2). The MAB to human ZP4 antibody did not cross-react with native mouse zona proteins.

\section{Fertility and taxon-specific recognition of human ZP4 transgenic eggs}

Five human ZP4 transgenic females and five normal controls were primed with pregnant mare serum gonadotropin and stimulated to ovulate eggs with human chorionic gonadotropin. Comparable numbers of eggs (average \pm s.E.M.) were recovered from the oviduct of normal $(23.5 \pm 2.7)$ and human ZP4 transgenic mice $(22.8 \pm 2.5)$. Fertility was determined by pairing five human $Z P 4$ transgenic with five normal FVB females of the same age and mating each pair with a normal male. Monitoring through several litters demonstrated that human ZP4 transgenic females had litters

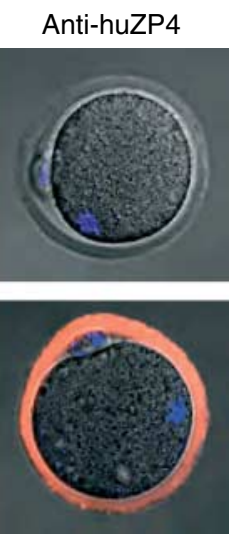

Figure 2 Confocal microscopy of ovulated eggs. Ovulated eggs from normal and human ZP4 transgenic females were stained with MABs specific to mouse ZP1, mouse ZP2, mouse ZP3, or human ZP4 and imaged by confocal microscopy. The zona pellucida surrounding human $Z P 4$ transgenic eggs contained ZP4, which was absent in normal eggs.

(9.2 \pm 0.84 pups) with a size comparable to normal females $(7.1 \pm 0.8$ pups). The transgene was successfully transmitted to the next generation in $41 \%$ of the pups in eight litters, which is close to the expected $50 \%$ Mendelian ratio (Table 1 ).

Ovulated eggs and two-cell embryos (wash controls) were collected from human ZP4 transgenic females after gonadotropin stimulation with or without mating, as appropriate. Eggs in cumulus were isolated from the oviduct and treated with hyaluronidase to remove somatic cells. Fertilized eggs were cultured overnight to obtain two-cell embryos. Groups of eggs and embryos were separated into two sets, which were incubated with either normal, capacitated epididymal mouse sperm, or capacitated human sperm from fertile male donors. After 30 min, eggs were washed with a widebore pipette to remove loosely adherent sperm using two-cell embryos, to which sperm do not bind above background levels, as negative controls (Fig. 3A); uninseminated, immature human oocytes served as positive controls (Fig. 3B). Mouse sperm readily attached to transgenic eggs (37.4 \pm 8.6/egg) and to normal (FVB) ovulated eggs (59.5 \pm 1.4 egg) (Fig. 3). Only the occasional human sperm bound to human ZP4 transgenic eggs ( $1.4 \pm 0.28 / \mathrm{egg})$, a number comparable to that observed binding to normal eggs $(0.67 \pm 0.22 / \mathrm{egg})$. Both human and mouse sperm attached to uninseminated, immature human oocytes (Fig. 3B). Similar results were observed even after $22 \mathrm{~h}$ of incubation (data not shown). Human sperm did not penetrate the 'humanized' zona pellucida and were not observed in the perivitelline space of transgenic eggs.

Table 1 Fertility of human ZP4 transgenic mice.

\begin{tabular}{lccl}
\hline & $\begin{array}{c}\text { Ovulated eggs } \\
\text { (average } \pm \text { s.E.M.) }\end{array}$ & $\begin{array}{c}\text { Litter size } \\
\text { (average } \pm \text { S.E.M.) }\end{array}$ & $\begin{array}{c}\text { Transgenic pups } \\
\text { (average } \pm \text { S.E.M.) }\end{array}$ \\
\hline Human ZP4 (5) & $22.8 \pm 2.5^{*}$ & $8.6 \pm 0.7^{+}$ & $41.1 \pm 10.4(\%)$ \\
FVB (5) & $23.5 \pm 2.7^{*}$ & $7.1 \pm 0.8^{\dagger}$ & ND \\
\hline
\end{tabular}

${ }^{*}{ }^{\dagger}$ Student's $t$-test indicates no statistical difference; $P<0.05$. 
A
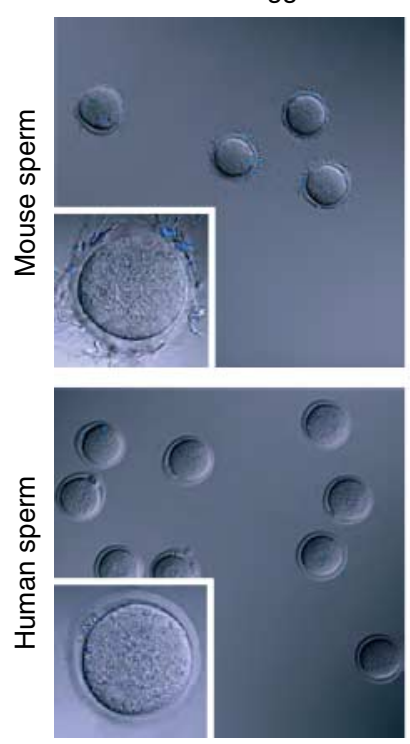

HuZP4 transgenic egg
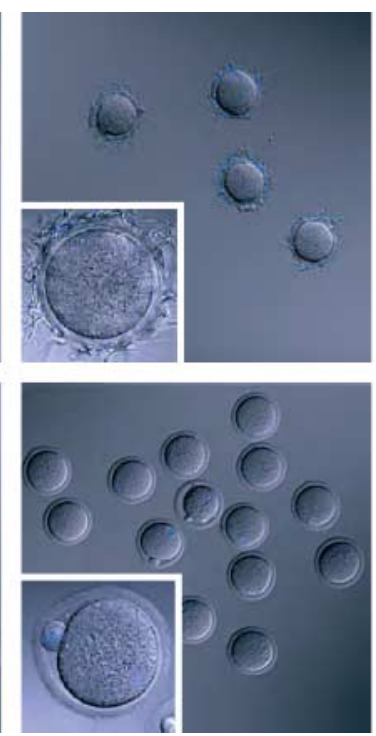

B

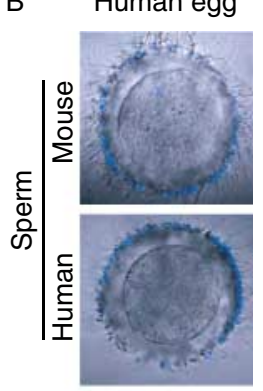

Figure 3 Taxon-specific sperm binding to ovulated eggs. (A) Ovulated eggs and two-cell embryos from normal and human $Z P 4$ transgenic females were incubated with capacitated epididymal mouse sperm or capacitated human sperm from fertile donors. Washes to remove nonadherent sperm were performed until three or fewer sperm were bound to control two-cell embryos. Insets are higher magnification of individual eggs from lower magnification field. Eggs, embryos, and sperm were stained with DAPI to detect DNA. (B) Same as (A), but with uninseminated, immature human oocytes.

\section{Discussion}

Human fertility remains a global issue in public health, both for those who wish to facilitate procreation through reproductive technologies and those who seek to limit population growth by contraception. A major step in fertilization is sperm-egg recognition that occurs between a motile, capacitated sperm and the surface of the zona pellucida surrounding recently ovulated eggs. It is an ideal point to affect human fertilization, but little is known about the molecular basis of this seminal event. In part because of ethical considerations and the practical challenges posed by the paucity of biological materials, it has been difficult to directly investigate fertilization in humans. Thus, investigators have sought to exploit other experimental systems to gain insights into the molecular basis of initial gamete interactions. The mouse model is particularly well established (Ikawa et al. 2010), but the recent observation that human zonae pellucidae contain an additional zona protein raises questions as to the adequacy of mice as a proxy for human fertility.

The human egg is larger than that of the mouse (120 vs $80 \mu \mathrm{m})$ and its zona pellucida is considerably thicker (12 vs $8 \mu \mathrm{m}$ ). Although the relative abundance of zona transcripts in the mouse oocyte has been established (Epifano et al. 1995), determination of the stoichiometry of proteins within the zona matrix varies with the method of interrogation (Bleil \& Wassarman 1980, Shimizu et al. 1983, Moos et al. 1995, Bauskin et al. 1999). At least three of the human zona proteins (ZP2, ZP3, and ZP4) are incorporated into the extracellular zona pellucida in transgenic mice and at least two (ZP2 and ZP3) can replace endogenous mouse proteins to support mouse fertilization. However, there are differences in how the human proteins participate in human-mouse chimeric zonae pellucidae. Normally, both mouse and human ZP2 are cleaved following fertilization (Moller \& Wassarman 1989, Bauskin et al. 1999) and the cleavage status of mouse ZP2 determines sperm-egg recognition independent of fertilization and cortical granule exocytosis (Gahlay et al. 2010). The cleavage site in mice is upstream of a di-acidic motif (LA $\downarrow D E N)$ and is conserved in humans (LA $\downarrow D D S)$. However, human ZP2 present in the human-mouse chimeric zona pellucida is not cleaved following fertilization, which preserves a zona structure to which mouse sperm bind (Rankin et al. 2003, Baibakov et al. 2007). Either the mouse protease has taxon specificity or the structure of the chimeric zona renders the site inaccessible to the cleaving enzyme. In a similar vein, mice lacking ZP1 still form a zona pellucida composed of mouse ZP2 and ZP3, which mouse sperm recognize and fertilize. However, the expression of the homologous human proteins in transgenic mice lacking endogenous mouse zona proteins is not sufficient to form a corresponding zona pellucida matrix composed of just human ZP2 and ZP3 (Galina Baibakov, unpublished results).

Human ZP2 and ZP3 are $60-71 \%$ identical to their murine homologues and, when expressed in transgenic mice, they are post-translationally modified and secreted prior to incorporation into the zona pellucida. Although no direct comparison of $\mathrm{O}$ - or $\mathrm{N}$-glycans in native and recombinant human zona proteins expressed in transgenic mice has been reported, the potential role of taxonspecific glycosylation in dictating the specificity of sperm-egg recognition has been an area of investigative interest (Dell et al. 2003, Chalabi et al. 2006). However, based on mobility on SDS-PAGE, human proteins 
expressed in transgenic mice are post-translationally modified to a similar extent to native human zona proteins (Rankin et al. 1998, 2003). In addition, there is accumulating evidence, based on mutation of putative attachment sites (Liu et al. 1995, Gahlay et al. 2010) and genetic disruptions of glycosyltransferases necessary to form candidate sugars (Ellies et al. 1998, Easton et al. 2000, Lowe \& Marth 2003, Shi et al. 2004, Williams et al. 2007), that zona glycan ligands may not be essential for mouse sperm-egg recognition.

Since the discovery of the fourth human zona protein (Lefièvre et al. 2004), a similar complement of proteins has been described in other mammals (Conner et al. 2005). $Z P 1$ and $Z P 4$ appear to have arisen as a result of gene duplication early in the vertebrate lineage after its divergence from fish, $\sim 650$ million years ago. The two genes can be considered paralogues, which usually evolve to different functions. The persistence of both implies that each has its own specialized and important function for that particular taxon. Despite variations in nomenclature for zona proteins within the literature, it appears that ZP4 has been implicated in mediating sperm binding in several different species. For example, recombinant rabbit ZP4 binds to the acrosome of rabbit sperm and antibodies, but not Fab fragments, inhibiting sperm binding (Prasad et al. 1996). Likewise, sperm attachment to the zona matrix has been attributed to ZP4 in humans (Chiu et al. 2008) and heterocomplexes of ZP4 with ZP3 in pigs (Yurewicz et al. 1998, Kanai et al. 2007).

These observations suggested possible involvement of ZP4 in other species, but the current data indicate that recombinant human ZP4 is not sufficient to support recognition of transgenic mouse eggs by human sperm under conditions in which human sperm attach to human oocytes. Recombinant human ZP4 is secreted and incorporated into the extracellular zona pellucida that appears normal in ovarian sections and ovulated eggs of transgenic mice. Based on their molecular mass, recombinant and native human ZP4 have overlapping isoforms, which may reflect subtle differences in glycosylation, but whether such differences affect structure or function remains to be determined. It will be important to complement these negative data (absence of human sperm binding) with positive results to validate mouse transgenesis as a physiological proxy for human gamete recognition. Thus, it will be of particular interest to determine whether improved assay conditions will support human sperm recognition of transgenic mouse eggs containing additional human zona proteins. Establishment of an experimental system in transgenic mice that supports human sperm recognition would not only provide insight into the molecular basis of gamete recognition, but would also establish a valuable diagnostic tool for the clinical evaluation of male infertility.

\section{Materials and Methods}

\section{Establishment of transgenic mouse lines}

Using DNA recombineering (recombination-mediated genetic engineering), human ZP4 (chromosome 1:236,111,332$236,122,955)$ was subcloned from BAC RP11-484B19 (CHORI, Oakland, CA, USA) into a bacterial plasmid (Liu et al. 2003). Oligonucleotide primers were designed to PCR amplify left (forward 5'-GCGGCCGCAACTCCACCCATTG-3'; reverse $5^{\prime}$-AAGCTTATGTGGCTTCCCTGACAC- $3^{\prime}$ ) and right (forward 5'-AAGCTTGCTGCTCAGCCATACTCT-3'; and reverse $5^{\prime}$-GTCGACCCTTCTCCCATTTACCC- $3^{\prime}$ ) arms bounded by Notl and Sall and separated by HindIII restriction enzyme sites. The left and right arms were subcloned to establish the retrieving vector, the integrity of which was confirmed by DNA sequence. The BAC was electroporated into SW102 cells growing at $32{ }^{\circ} \mathrm{C}$ and its presence was confirmed by PCR of human ZP4 exons. The isolated retrieving vector, linearized by digestion with HindIII, was then electroporated into SW102 cells containing BAC DNA and recombination was induced (15 min, $42{ }^{\circ} \mathrm{C}$ ). Colonies were selected by antibiotic resistance and the retrieval of human $Z P 4$ was confirmed by DNA sequence.

After digestion with Notl and Sall, the human ZP4 genomic DNA fragment was gel purified and injected into the pronucleus of one-cell embryos to establish transgenic mouse lines (Rankin et al. 1998). The transgene was detected by PCR of tail DNA using exon-specific oligonucleotides (forward primer 5'-GGTTTTCACTCTCCCACCAC-3'; reverse primer 5'-CAGGACAGGTCACCACACAG- $\left.3^{\prime}\right)$. The presence of the transgene in 5 of 25 pups $(20 \%)$ was confirmed by Southern hybridization using full-length human ZP4 cDNA (Chakravarty et al. 2005) labeled with [ $\left.{ }^{32} \mathrm{P}\right] \mathrm{dCTP}$ (Rankin et al. 1998). For histological analysis, ovaries were collected from 3- to 4-week-old normal and transgenic females, fixed in 3\% glutaraldehyde, embedded in plastic, and stained with periodic-acid Schiff's reagent (Rankin et al. 2001).

\section{PCR}

Total RNA was isolated from 4- to 8-week-old mouse tissue with RNeasy mini kit (Qiagen), treated with Dnasel, and used as a template for ssDNA synthesis with SuperScript First-Strand Synthesis (Invitrogen). Human ZP4 (above exon primers) and GAPDH (forward primer 5'-ACTCCACTCACGGCAAATTC-3'; reverse primer $5^{\prime}$-CACATTGGGGGTAGGAACAC- $3^{\prime}$ ) were used to produce PCR products that were separated by gel electrophoresis and stained with ethidium bromide (Ohsugi et al. 2008).

\section{In situ hybridization}

Ovaries (15 days old) were isolated from normal and transgenic mice and fixed in OCT (Sakura-Finetek, Torrance, CA, USA). Sections $(4 \mu \mathrm{m})$ were mounted on glass slides, fixed in $4 \%$ formaldehyde (Sigma-Aldrich) in PBS, blocked with triethanolamine/acetic anhydride, washed, and dehydrated through an ethanol series. Sense and anti-sense cRNA (1-778 nt, beginning at the AUG) derived from human ZP4 CDNA was labeled in vitro with ${ }^{35} \mathrm{~S}$-UTP according to the manufacturer's instructions (Ambion, Austin, TX, USA). Sections were hybridized overnight 
$\left(55^{\circ} \mathrm{C}, 50 \%\right.$ formamide, $0.3 \mathrm{M} \mathrm{NaCl}, 20 \mathrm{mM}$ Tris- $\mathrm{HCl}, \mathrm{pH}$ 7.4, $5 \mathrm{mM}$ EDTA, $10 \mathrm{mM} \mathrm{NaH}{ }_{2} \mathrm{PO}_{4}, 10 \%$ dextran sulfate $1 \times$ Denhardt's, $50 \mu \mathrm{g} / \mathrm{ml}$ total yeast RNA, and $5-8 \times 10^{7}$ c.p.m. $/ \mathrm{ml}$

${ }^{35}$ S-labeled probe (Phylogeny, Columbus, OH, USA)). After stringent washes, digestion with Rnase, and emulsion autoradiography, using Kodak D-19 as a developer (Kodak), slides were lightly counterstained with cresyl violet and imaged using bright- and darkfield microscopy (Rankin et al. 2003).

\section{Immunoblots}

Uninseminated, immature, nonviable human oocytes, obtained from Shady Grove Fertility Center, Rockville, MD, USA, were washed three times in PBS/protease inhibitors/0.3\% polyvinylpyrrolidone prior to a quick freeze and storage in the vapor phase of liquid nitrogen. The human oocytes as well as ovulated eggs from normal and transgenic mice were used for immunoblots (Rankin et al. 2003) that were probed with a MAB specific to human ZP4 (1:500, overnight, $\left.4{ }^{\circ} \mathrm{C}\right)$ (Bukovsky et al. 2008).

\section{Confocal microscopy}

Transgenic mice were stimulated with gonadotropins to recover ovulated eggs (three independently obtained samples of 6-8 eggs per mouse line), which were fixed in $2 \%$ paraformaldehyde and stained with MABs to mouse ZP1, ZP2, ZP3 (Rankin et al. 1998), and human ZP4 (Bukovsky et al. 2008). Images were obtained by confocal microscopy (Rankin et al. 2003).

\section{Fertility and sperm binding to ovulated eggs}

Fertility was assayed by mating transgenic and FVB females with FVB males (2:1). Taxon-specific sperm binding was initially determined in an assay in which mouse eggs and two-cell embryos were used as negative controls for human and mouse sperm binding respectively. Mouse eggs served as a positive control for mouse sperm binding, but these assays lacked a positive control for human sperm binding (Rankin et al. 2003, Hoodbhoy et al. 2005). Therefore, a modified assay was developed in which uninseminated, immature human oocytes served as a positive binding control for human sperm.

Mouse oocytes/embryos were collected as described earlier (Hoodbhoy et al. 2005) and uninseminated, immature human oocytes were obtained from Shady Grove Fertility Clinic, Rockville, MD, USA. Samples (1 ml) of liquefied human semen (Genetics and IVF Institute Cryobanks, Fairfax, VA, USA) were added to a column containing $500 \mu \mathrm{l}$ of a mixture (80:20) of PureSperm silica suspension (Nidacon, Molndal, Sweden) and human tubal fluid (HTF, Specialty Media/Millipore, Billerica, MA, USA) supplemented with 5\% BSA. After centrifugation $(20 \mathrm{~min} \times 500 \mathrm{~g})$, sperm pellets were resuspended in 100-200 $\mu$ l of the HTF/BSA. Two to four resuspended sperm samples from different donors were mixed and 300-400 $\mu$ l were placed in a center-well organ culture dish (BD Falcon, 353037, Franklin Lakes, NJ, USA) surrounded by a ring of water. Mouse eggs/embryos and uninseminated, immature human oocytes were then added and co-incubated $\left(90 \% \mathrm{~N}_{2}, 5 \% \mathrm{O}_{2}, 5 \% \mathrm{CO}_{2}, 37^{\circ} \mathrm{C}\right)$ for $4 \mathrm{~h}$ to ensure capacitation of human sperm. Eggs/embryos/oocytes were washed by transfer pipette $(0.35 \mathrm{~mm}$ tip) into a single fresh drop (20 $\mu \mathrm{l})$ of HTF/BSA. Human oocytes and mouse eggs served as positive and negative wash controls respectively. All experiments were conducted in triplicate. Even without the single wash, human sperm did not bind to mouse eggs.

Mouse sperm were collected from the cauda epididymis by macerating the tissue in a dish of HTF and capacitated $(90 \%$ $\mathrm{N}_{2}, 5 \% \mathrm{O}_{2}, 5 \% \mathrm{CO}_{2}, 37^{\circ} \mathrm{C}$ ) for 40 min (Rankin et al. 2003). Aliquots $(\sim 50 \mu \mathrm{l})$ of capacitated sperm were added to centerwell organ culture dishes already containing uninseminated, immature human oocytes, mouse eggs, and two-cell embryos in $350 \mu \mathrm{l}$ of HTF. After incubation (30 min) with mouse sperm, mouse eggs/embryos and human oocytes were washed sequentially by transfer pipette into fresh drops of HTF $(20 \mu \mathrm{l})$ until only two to five sperm bound to two-cell mouse embryos, which served as negative controls. Mouse and human samples were fixed by adding $20 \mu \mathrm{l}$ of $4 \%$ paraformaldehyde and stained with Hoechst to identify nuclei. Binding was assayed by collapsing the Z-stack of $5 \mu \mathrm{m}$ optical sections to capture all bound sperm and results reflect the average \pm s.E.M. of the mean from three independently obtained samples each containing 6-12 mouse eggs. These experiments were conducted in compliance with the guidelines of the Animal Care and Use Committee of the National Institutes of Health under a Division of Intramural Research, NIDDK-approved animal study protocol. The Office of Human Subject Research determined that federal regulations did not apply to the anonymous human sperm and egg samples.

\section{Declaration of interest}

The authors declare that there is no conflict of interest that could be perceived as prejudicing the impartiality of the research reported.

\section{Funding}

Dr B Yauger was supported by the Combined Federal Fellowship in Reproductive Endocrinology and Infertility, and this research was supported by the Intramural Research Program of the National Institutes of Health, NIDDK, Bethesda, MD.

\section{Acknowledgements}

We appreciate the gift of human ZP4 MAB and cDNA from Dr Satish K Gupta, the pronuclear injections by Ms Lyn Gauthier to establish the transgenic mice, and confocal imagining by Dr Boris Baibakov.

\section{References}

Baibakov B, Gauthier L, Talbot P, Rankin TL \& Dean J 2007 Sperm binding to the zona pellucida is not sufficient to induce acrosome exocytosis. Development 134 933-943. (doi:10.1242/dev.02752)

Bauskin AR, Franken DR, Eberspaecher U \& Donner P 1999 Characterization of human zona pellucida glycoproteins. Molecular Human Reproduction 5 534-540. (doi:10.1093/molehr/5.6.534)

Bedford JM 1977 Sperm/egg interaction: the specificity of human spermatozoa. Anatomical Record 188 477-488. (doi:10.1002/ar.1091880407) 
Bleil JD \& Wassarman PM 1980 Structure and function of the zona pellucida: identification and characterization of the proteins of the mouse oocyte's zona pellucida. Developmental Biology 76 185-202. (doi:10.1016/0012-1606(80)90371-1)

Boja ES, Hoodbhoy T, Fales HM \& Dean J 2003 Structural characterization of native mouse zona pellucida proteins using mass spectrometry. Journal of Biological Chemistry 278 34189-34202. (doi:10.1074/jbc. M304026200)

Bukovsky A, Gupta SK, Bansal P, Chakravarty S, Chaudhary M, Svetlikova M, White RS, Copas P, Upadhyaya NB, Van Meter SE et al. 2008 Production of monoclonal antibodies against recombinant human zona pellucida glycoproteins: utility in immunolocalization of respective zona proteins in ovarian follicles. Journal of Reproductive Immunology 78 102-114. (doi:10.1016/j.jri.2007.10.004)

Chakravarty S, Suraj K \& Gupta SK 2005 Baculovirus-expressed recombinant human zona pellucida glycoprotein-B induces acrosomal exocytosis in capacitated spermatozoa in addition to zona pellucida glycoprotein-C. Molecular Human Reproduction 11 365-372. (doi:10. 1093/molehr/gah165)

Chalabi S, Panico M, Sutton-Smith M, Haslam SM, Patankar MS, Lattanzio FA, Morris HR, Clark GF \& Dell A 2006 Differential $O$-glycosylation of a conserved domain expressed in murine and human ZP3. Biochemistry 45 637-647. (doi:10.1021/bi0512804)

Chiu PC, Wong BS, Chung MK, Lam KK, Pang RT, Lee KF, Sumitro SB, Gupta SK \& Yeung WS 2008 Effects of native human zona pellucida glycoproteins 3 and 4 on acrosome reaction and zona pellucida binding of human spermatozoa. Biology of Reproduction 79 869-877. (doi:10. 1095/biolreprod.108.069344)

Conner SJ, Lefievre L, Hughes DC \& Barratt CL 2005 Cracking the egg: increased complexity in the zona pellucida. Human Reproduction 20 1148-1152. (doi:10.1093/humrep/deh835)

Dell A, Chalabi S, Easton RL, Haslam SM, Sutton-Smith M, Patankar MS, Lattanzio F, Panico M, Morris HR \& Clark GF 2003 Murine and human zona pellucida 3 derived from mouse eggs express identical $O$-glycans. PNAS 100 15631-15636. (doi:10.1073/pnas.2635507100)

Easton RL, Patankar MS, Lattanzio FA, Leaven TH, Morris HR, Clark GF \& Dell A 2000 Structural analysis of murine zona pellucida glycans Evidence for the expression of core 2-type O-glycans and the $\mathrm{Sd}(\mathrm{a})$ antigen. Journal of Biological Chemistry 275 7731-7742. (doi:10.1074/ jbc.275.11.7731)

Ellies LG, Tsuboi S, Petryniak B, Lowe JB, Fukuda M \& Marth JD 1998 Core 2 oligosaccharide biosynthesis distinguishes between selectin ligands essential for leukocyte homing and inflammation. Immunity 9 881-890. (doi:10.1016/S1074-7613(00)80653-6)

Epifano O, Liang L-F, Familari M, Moos MC Jr \& Dean J 1995 Coordinate expression of the three zona pellucida genes during mouse oogenesis. Development 121 1947-1956.

Gahlay G, Gauthier L, Baibakov B, Epifano O \& Dean J 2010 Gamete recognition in mice depends on the cleavage status of an egg's zona pellucida protein. Science 329 216-219. (doi:10.1126/science. 1188178)

Govind CK, Hasegawa A, Koyama K \& Gupta SK 2000 Delineation of a conserved B cell epitope on bonnet monkey (Macaca radiata) and human zona pellucida glycoprotein-B by monoclonal antibodies demonstrating inhibition of sperm-egg binding. Biology of Reproduction 62 67-75. (doi:10.1095/biolreprod62.1.67)

Hoodbhoy T, Joshi S, Boja ES, Williams SA, Stanley P \& Dean J 2005 Human sperm do not bind to rat zonae pellucidae despite the presence of four homologous glycoproteins. Journal of Biological Chemistry 280 12721-12731. (doi:10.1074/jbc.M413569200)

Ikawa M, Inoue N, Benham AM \& Okabe M 2010 Fertilization: a sperm's journey to and interaction with the oocyte. Journal of Clinical Investigation 120 984-994. (doi:10.1172/JCl41585)

Kanai S, Yonezawa N, Ishii Y, Tanokura M \& Nakano M 2007 Recombinant bovine zona pellucida glycoproteins ZP3 and ZP4 coexpressed in Sf9 cells form a sperm-binding active hetero-complex. FEBS Journal 274 5390-5405. (doi:10.1111/j.1742-4658.2007.06065.x)

Lefièvre L, Conner SJ, Salpekar A, Olufowobi O, Ashton P, Pavlovic B, Lenton W, Afnan M, Brewis IA, Monk M et al. 2004 Four zona pellucida glycoproteins are expressed in the human. Human Reproduction 19 1580-1586. (doi:10.1093/humrep/deh301)
Liu C, Litscher S \& Wassarman PM 1995 Transgenic mice with reduced numbers of functional sperm receptors on their eggs reproduce normally. Molecular Biology of the Cell 6 577-585.

Liu P, Jenkins NA \& Copeland NG 2003 A highly efficient recombineeringbased method for generating conditional knockout mutations. Genome Research 13 476-484. (doi:10.1101/gr.749203)

Lowe JB \& Marth JD 2003 A genetic approach to mammalian glycan function. Annual Review of Biochemistry 72 643-691. (doi:10.1146/ annurev.biochem.72.121801.161809)

Moller CC \& Wassarman PM 1989 Characterization of a proteinase that cleaves zona pellucida glycoprotein ZP2 following activation of mouse eggs. Developmental Biology 132 103-112. (doi:10.1016/00121606(89)90209-1)

Moos J, Faundes D, Kopf GS \& Schultz RM 1995 Composition of the human zona pellucida and modifications following fertilization. Human Reproduction 10 2467-2471.

Ohsugi M, Zheng P, Baibakov B, Li L \& Dean J 2008 Maternally derived FILIA-MATER complex localizes asymmetrically in cleavage-stage mouse embryos. Development 135 259-269. (doi:10.1242/dev.011445)

O'Rand MG 1988 Sperm-egg recognition and barriers to interspecies fertilization. Gamete Research 19 315-328. (doi:10.1002/mrd. 1120190402)

Prasad SV, Wilkins B, Skinner SM \& Dunbar BS 1996 Evaluating zona-pellucida structure and function using antibodies to rabbit 55 kDa ZP protein expressed in baculovirus expression system. Molecular Reproduction and Development 43 519-529. (doi:10.1002/(SICI)10982795(199604)43:4<519::AID-MRD15>3.0.CO;2-U)

Rankin TL, Tong Z-B, Castle PE, Lee E, Gore-Langton R, Nelson LM \& Dean J 1998 Human ZP3 restores fertility in Zp3 null mice without affecting order-specific sperm binding. Development 125 2415-2424.

Rankin T, Talbot P, Lee E \& Dean J 1999 Abnormal zonae pellucidae in mice lacking ZP1 result in early embryonic loss. Development 126 3847-3855.

Rankin TL, O'Brien M, Lee E, Wigglesworth KEJJ \& Dean J 2001 Defective zonae pellucidae in Zp2 null mice disrupt folliculogenesis, fertility and development. Development 128 1119-1126.

Rankin TL, Coleman JS, Epifano O, Hoodbhoy T, Turner SG, Castle PE, Lee E, Gore-Langton R \& Dean J 2003 Fertility and taxon-specific sperm binding persist after replacement of mouse 'sperm receptors' with human homologues. Developmental Cell 5 33-43. (doi:10.1016/S15345807(03)00195-3)

Shi S, Williams SA, Seppo A, Kurniawan H, Chen W, Zhengyi Y, Marth JD \& Stanley P 2004 Inactivation of the Mgatl gene in oocytes impairs oogenesis, but embryos lacking complex and hybrid N-glycans develop and implant. Molecular and Cellular Biology 24 9920-9929. (doi:10. 1128/MCB.24.22.9920-9929.2004)

Shimizu S, Tsuji M \& Dean J 1983 In vitro biosynthesis of three sulfated glycoproteins of murine zonae pellucidae by oocytes grown in follicle culture. Journal of Biological Chemistry 258 5858-5863.

Topper EK, Kruijt L, Calvete J, Mann K, Topfer-Petersen E \& Woelders H 1997 Identification of bovine zona pellucida glycoproteins. Molecular Reproduction and Development 46 344-350. (doi:10.1002/(SICI)10982795(199703)46:3 < 344::AID-MRD13>3.0.CO;2-Z)

Williams SA, Xia L, Cummings RD, McEver RP \& Stanley P 2007 Fertilization in the mouse does not require terminal galactose or $\mathrm{N}$-acetylglucosamine on the zona pellucida glycans. Journal of Cell Science 120 1341-1349. (doi:10.1242/jcs.004291)

Yanagimachi R 1994 Mammalian fertilization. In The Physiology of Reproduction, pp 189-317. Eds E Knobil \& J Neil. New York: Raven Press.

Yurewicz EC, Sacco AG, Gupta SK, Xu N \& Gage DA 1998 Heterooligomerization-dependent binding of pig oocyte zona pellucida glycoproteins ZPB and ZPC to boar sperm membrane vesicles. Journal of Biological Chemistry 273 7488-7494. (doi:10.1074/jbc.273. 13.7488)

Received 24 May 2010

First decision 16 June 2010

Revised manuscript received 7 December 2010

Accepted 20 December 2010 